\title{
Variations in refractive optical properties of nylon 66 fibres under different thermal conditions
}

\author{
M.M. El-Nicklawy, R.El-Agmy, A.F. Hassan, \\ Magdy El-Hagary and Amany Adel \\ Physics Department, Faculty of Science 11792, Helwan University, Cairo-Egypt. \\ E-mail: redaagmy@yahoo.com
}

Received: 17.12.2009

After revision: 20.06.2010

\begin{abstract}
In this work the changes in the refractive optical properties of nylon 66 fibres occurring due to heating in water and detergent solutions of different concentrations have been studied with the aid of interferometric techniques. Multiple-beam Fizeau fringes for the two alternative input light polarisations have been used in order to determine the refractive indices of the core and skin, their mean value, and the corresponding birefringences.
\end{abstract}

Keywords: nylon 66 fibres, polymers, refractive index, interference, birefringence

PACS: $42.25 . \mathrm{Hz}, 42.25 . \mathrm{Lc}, 42.70 . \mathrm{Jk}$

UDC: 535.327

\section{Introduction}

Although the production of synthetic polymers for textile and other industries has begun more than 40 years ago, it is still growing. This is because the properties of these materials can be changed according to application desired. The assessment of optical properties of the corresponding fibres seems to be very important. This would provide information about the degree of orientation of these particular molecular systems, which manifest great mechanical, thermal and chemical resistances. Moreover, knowledge of this kind is of great relevance in relation to modern techniques for quality control employed in many industrial processes [1].

A modern trend in the researches and applications of optical fibres is modification of their physical properties. One of the methods for performing this involves the effect of heating process occurring in different solutions, and a consequent cooling down to the room temperature. Several studies have been reported on the effect of annealing, quenching and mechanical processing on the structure of $\mathrm{s}$ ynthetic fibres [2, 3, 4-7]. Many authors have employed interferometric methods when studying the fibrous materials (see, e.g., $[8,9-11]$ ). In this respect we should mention that the refractive index and the optical birefringence of polymeric optical fibres 
are the most important parameters characterising the structure of the corresponding material.

In the present work, the changes appearing in the optical properties of nylon 66 fibres as a result of their heating in the water and/or the chemical detergent solutions of different concentrations have been determined with an interferometric technique. Namely, multiple-beam Fizeau fringes observed for the 'parallel' $(\|)$ and 'perpendicular' $(\perp)$ incident light polarisations have been used in order to determine the skin refractive indices $\left(n_{s}^{\|, \perp}\right)$, the core refractive indices $\left(n_{c}^{\|, \perp}\right)$, the corresponding mean refractive indices $\left(n_{a}^{\|, \perp}\right)$, and the birefringence $\left(\Delta n_{s, c, a}\right)$ of the fibres mentioned above.

\section{Experimental techniques, results and discussion}

\subsection{Experimental setup}

An optical setup for producing multiple-beam Fizeau fringes in the transmitted light is shown in Fig. 1. A parallel beam of monochromatic light is incident normally at a wedge interferometer placed on a microscope stage. The wedge interferometer consists of two circular, partially reflecting optical plates having a diameter of $4.5 \mathrm{~cm}$, a thickness of $19 \mathrm{~mm}$, and flatness not worse than $\pm 0.01 \mu \mathrm{m}$. The reflection coefficients of the upper and lower mirrors were about $80 \%$ and $75 \%$, respectively. The coating was prepared by thermal evaporation of spec-pure silver in a vacuum better than $10^{-4}$ torr, in order to produce multiple-beam Fizeau fringes in the transmitted light. As seen from Fig. 1, the wedge was illuminated from a lower side, i.e. from a side of the horizontal mirror.

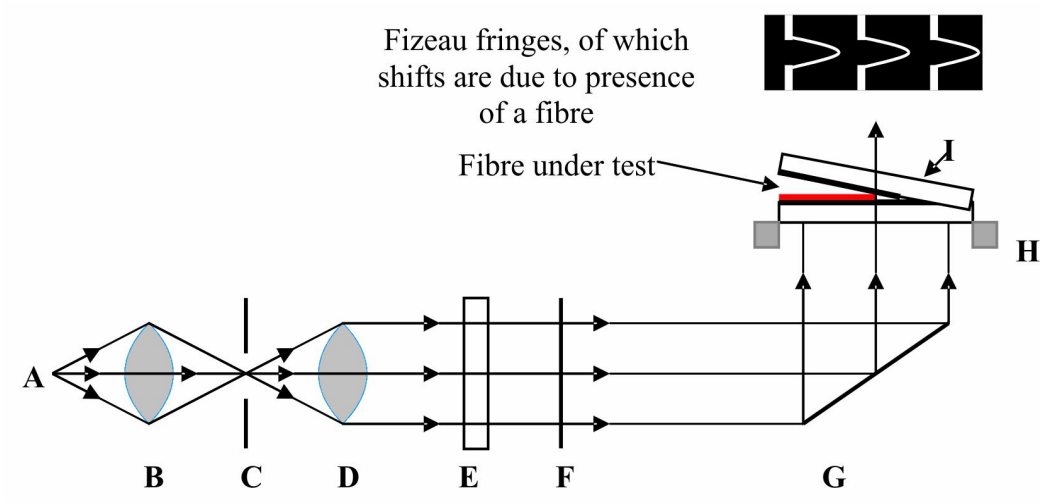

Fig. 1. Optical arrangement for producing multiple-beam Fizeau fringes in the transmitted light: A - mercury lamp, B - condenser lens, C - iris diaphragm, D - collimating lens, E - polariser, F - monochromatic filter, $\mathrm{G}$ - reflecting mirror, $\mathrm{H}$ - microscope stage, and I - silvered liquid wedge interferometer .

A drop of a liquid (a mixture of $\alpha$-promonapthalene and a paraffin oil), with the refractive index $n_{L}$ close to that of the most outer fibre's skin, was put on the silvered face of the lower optical flat as an immersion liquid. The fibre was immersed in the liquid and the upper optical flat was then introduced to form a wedge interferometer. Both the gap thickness and the wedge angle could be adjusted in order to form the sharpest fringes 
normal to the fibre. A linear polariser was inserted into a path of the light beam, allowing us to polarise the incident light parallel or perpendicular to the fibre axis.

\subsection{Sample preparation}

Samples of nylon 66 (I.C.I. polyamide 66, corded and combed) fibre were immersed in two glass bottles containing different liquids. These liquids were a water and a detergent solution (x-tra, with the following ingredients: $15-30 \%$ of phosphates, $5-15 \%$ of anionic surfactants and oxygen-based bleaching agents, $<5 \%$ of non-ionic surfactants, cationic surfactants, polycarboxylates and zeolites, as well as optical brighteners, perfumes, and enzymes). The glass bottles were heated in a temperature-controlled bath (CRIOTERM, 10.80). The temperature was changed from 30 to $100^{\circ} \mathrm{C}$ and the heating times varied in the region of $1-10 \mathrm{~h}$. Then the samples were left for cooling and drying at the room temperature $\left(25 \pm 1^{\circ} \mathrm{C}\right)$.

\subsection{Determination of refractive indices and birefringence for different fibre layers}

Our task is to determine the refractive index of each layer, $n_{k}$, of a cylindrical fibre basing on the fringe shift $\Delta Z$ measured at a point $x$ along the diameter of a multi-skin fibre. In case of the simplest skin-core fibre, one can obtain the following theoretical expression reported in the works $[10,11]$ :

$$
\begin{aligned}
(\lambda / 4 h) \Delta Z & =\left(n_{s}^{\|}-n_{L}\right)\left(r_{s}^{2}-x^{2}\right)^{1 / 2} \\
& +\left(n_{c}^{\|}-n_{s}^{\|}\right)\left(r_{c}^{2}-x^{2}\right)^{1 / 2},
\end{aligned}
$$

where $r_{s}$ and $r_{c}$ are the radii of respectively the skin and the core, $n_{s}^{\|}$and $n_{c}^{\|}$their refractive indices for a plane-polarised light with the polarisation direction parallel to the fibre axis, $n_{L}$ denotes the refractive index of the immersion liquid, $h$ the liquid interfering spacing, and $\lambda$ the light wavelength. A formula analogous to Eq. (1) should be used if the light polarisation is perpendicular to the fibre axis. In this geometry, the refractive indices $n_{s}^{\perp}$ and $n_{c}^{\perp}$ could be determined. Finally, the birefringence represents a difference between the refractive indices corresponding to the parallel and perpendicular polarisation directions, i.e. $\Delta n=n^{\|}-n^{\perp}$.

\subsection{Mean refractive index $n_{a}$}

Let a fibre core having the thickness $t_{c}$ and the refractive index $n_{c}$ be surrounded by a skin layer, with the thickness $t_{s}$ and the refractive index $n_{s}$. Then the mean refractive index $n_{a}$ of the fibre may be calculated using the following formula $[10,11]$ :

$$
n_{a}=n_{c} \frac{t_{c}}{t_{f}}+n_{s} \frac{t_{s}}{t_{f}}
$$

with $t_{f}=t_{s}+t_{c}$ denoting the whole fibre thickness. 


\subsection{Refractive indices of unheated nylon 66 fibres}

Plates 1 show sample microinterferograms of the multiple-beam Fizeau fringes observed at the room temperature $\left(25 \pm 1^{\circ} \mathrm{C}\right)$ in the transmitted light for the case of thermally untreated nylon 66 fibres. Here a monochromatic light $(546.1 \mathrm{~nm})$ has been used, with the polarisation parallel (Plate 1a) and perpendicular (Plate 1b) to the fibre axis. One can easily notice that the interference shift is directed towards a smaller gap, i.e. we have $n_{L}<n_{s}^{\|, \perp}$ and $n_{s}^{\|, \perp}<n_{c}^{\|, \perp}$ (see also Table 1).
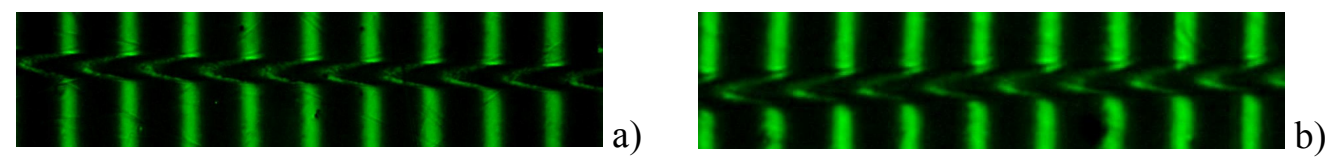

Plate 1. Microinterferograms of multiple-beam Fizeau fringes observed at the room temperature $\left(25^{\circ} \mathrm{C}\right)$ in the transmitted light, using the untreated nylon 66 fibres. The wavelength of monochromatic light is $\lambda=546.1 \mathrm{~nm}$ and the polarisation is parallel (a) and perpendicular (b) to the fibre axis.
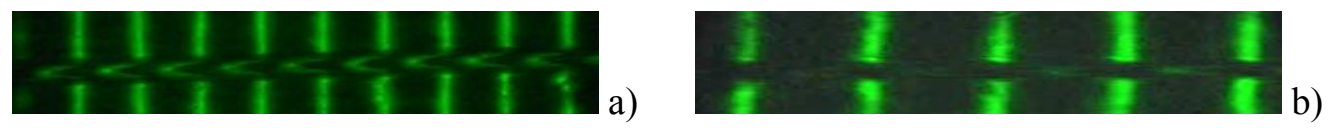

Plate 2. Microinterferograms of multiple-beam Fizeau fringes observed in the transmitted light, using the nylon 66 fibres kept in water for $2 \mathrm{~h}(\mathrm{a})$ and $9 \mathrm{~h}$ (b) at $80^{\circ} \mathrm{C}$. The wavelength of monochromatic light is $\lambda=546.1 \mathrm{~nm}$ and the polarisation is parallel to the fibre axis.

Table 1. Refractive indices measured for the case of untreated nylon 66 fibres (the error is estimated to be $\pm 5 \%$ ).

\begin{tabular}{|c|c|c|c|c|}
\hline Plate number & $n_{L}$ & $n_{s}$ & $n_{c}$ & $n_{a}$ \\
\hline $1 \mathrm{a}$ & 1.569 & 1.5698 & 1.5693 & 1.5696 \\
\hline $1 \mathrm{~b}$ & 1.513 & 1.5144 & 1.5127 & 1.5135 \\
\hline
\end{tabular}

\subsection{Refractive indices of nylon 66 fibres heated in the water and detergent}

We have also determined the refractive indices $n_{s}^{\|}, n_{c}^{\|}$and $n_{s}^{\perp}, n_{c}^{\perp}$ of the fibre layers, together with the $n_{a}^{\|}$and $n_{a}^{\perp}$ parameters, in the conditions when the fibres have been preliminarily heated for different periods. Further on, we will denote the parameters obtained after heating in the water with the symbol $(*)_{\mathrm{w}}$ and that obtained for the detergent solution with the symbol $(*)_{\text {sol }}$.

Plate 2 shows microinterferograms of the multiple-beam Fizeau fringes observed in the transmitted light in the case when the nylon 66 fibres have been heated in the water (the constant temperature $80^{\circ} \mathrm{C}$, and the time durations 2 and $9 \mathrm{~h}$ ). The light of the same wavelength $\lambda=546.1 \mathrm{~nm}$ has been used, with the polarisation direction parallel to the fibre axis. The refractive index of the immersion liquid is then equal to $n_{L}=1.569$ at $30 \pm 1^{\circ} \mathrm{C}$ (see also Table 1). 

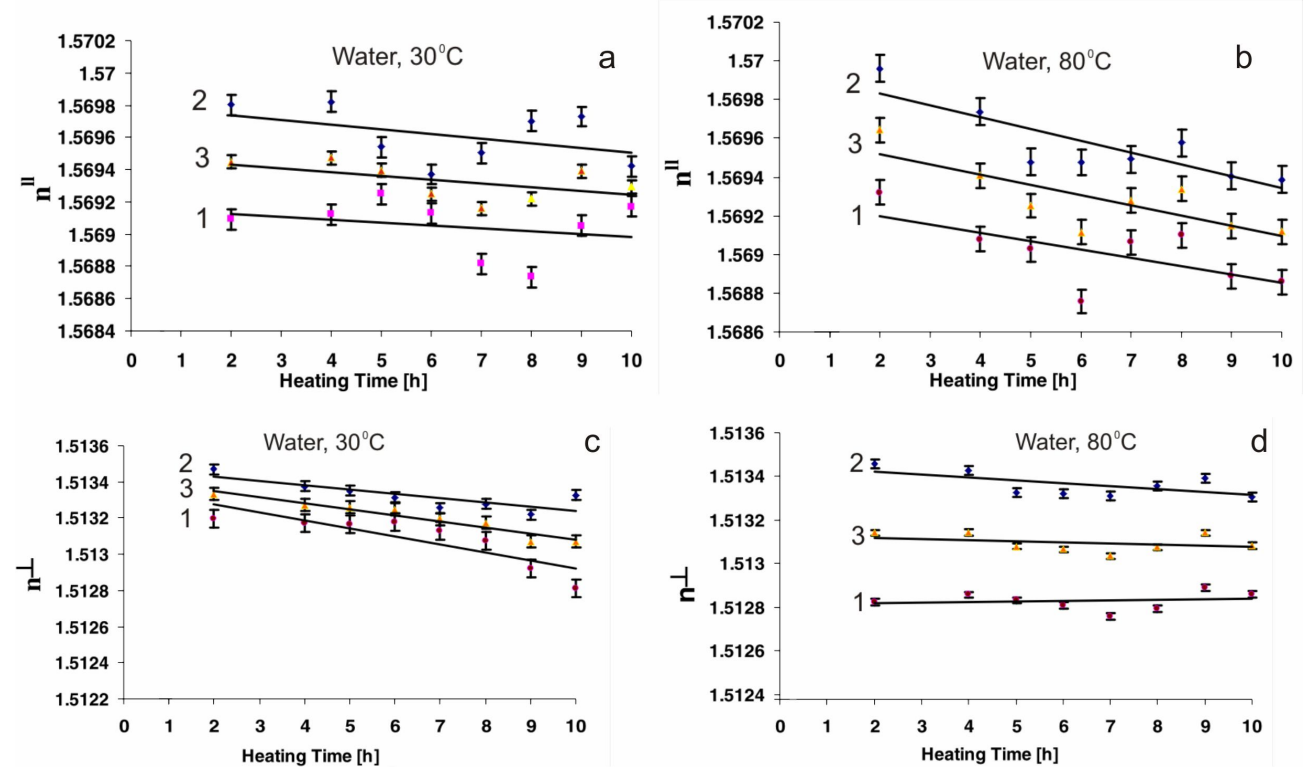

Fig. 2. 'Parallel' and 'perpendicular' refractive indices of the heated nylon fibres placed into the water versus heating time. The temperature is $30^{\circ} \mathrm{C}(\mathrm{a}, \mathrm{C})$ and $80^{\circ} \mathrm{C}$ (b, d) $\left(1-n_{s}^{\|, \perp}, 2-n_{c}^{\|, \perp}\right.$ and $\left.3-n_{a}^{\|, \perp}\right)$.
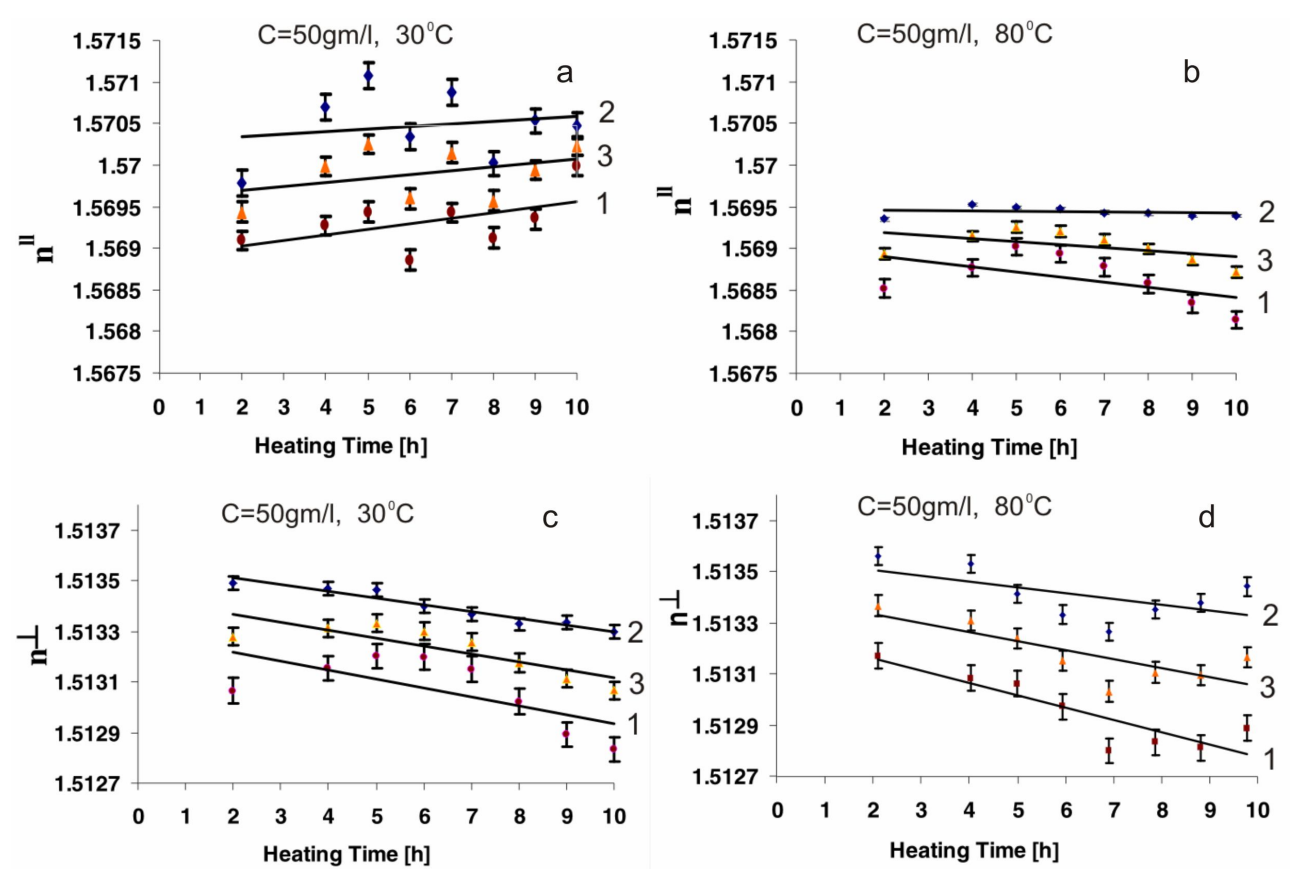

Fig. 3. 'Parallel' and 'perpendicular' refractive indices of the heated nylon 66 fibres placed into the detergent solution versus heating time. The temperature is $30^{\circ} \mathrm{C}$ (a, c) and $80^{\circ} \mathrm{C}(\mathrm{b}, \mathrm{d})\left(1-n_{s}^{\|, \perp}, 2-n_{c}^{\|, \perp}\right.$ and $\left.3-n_{a}^{\|, \perp}\right)$.

In Fig. 2, (temperature behaviour) the 'parallel' and 'perpendicular' refractive indices $\left(n_{s}^{\|, \perp}\right)_{\mathrm{w}},\left(n_{c}^{\|, \perp}\right)_{\mathrm{w}}$ and $\left(n_{a}^{\|, \perp}\right)_{\mathrm{w}}$, measured for the nylon fibres heated in the water, are displayed versus the heating time. Here we deal with the two different temperatures 
$\left(30^{\circ} \mathrm{C}\right.$ and $\left.80^{\circ} \mathrm{C}\right)$ and a number of heating times $(2-10 \mathrm{~h})$. The change of refractive indices $n_{s, c, a}^{\perp}$ measured at $80^{\circ} \mathrm{C}$ are within the error of measurements. Fig. 3 shows the behaviour of the 'parallel' and 'perpendicular' refractive indices $\left(n_{s}^{\|, \perp}\right)_{\text {sol }},\left(n_{c}^{\|, \perp}\right)_{\text {sol }}$ and $\left(n_{a}^{\|, \perp}\right)_{\text {sol }}$ detected for the nylon 66 fibres heated in the chemical solution with the concentration of $c=50 \mathrm{gm} / \mathrm{l}$, with the temperature being a parameter. In Fig. 4, we present the concentration changes in the 'parallel' and 'perpendicular' refractive indices $\left(n_{s}^{\|, \perp}\right)_{\text {sol }},\left(n_{c}^{\|, \perp}\right)_{\text {sol }}$ and $\left(n_{a}^{\|, \perp}\right)_{\text {sol }}$ observed for the nylon 66 fibres at different temperatures $\left(30,50\right.$ and $\left.80^{\circ} \mathrm{C}\right)$ and a fixed heating time $(1 \mathrm{~h})$. No significant variations are seen from Fig. 4 in the refractive indices measured at $30^{\circ} \mathrm{C}$ and $50^{\circ} \mathrm{C}$. The concentration dependences of the 'parallel' refractive indices for the case of detergent solution and different heating conditions are shown in Fig. 5. Here the dependences at longer heating times are different, when compare to the results presented in Fig. 4.

Let us finally touch upon the birefringence, which yields information about the anisotropy and orientation of polymer molecular chains with respect to the fibre axis.
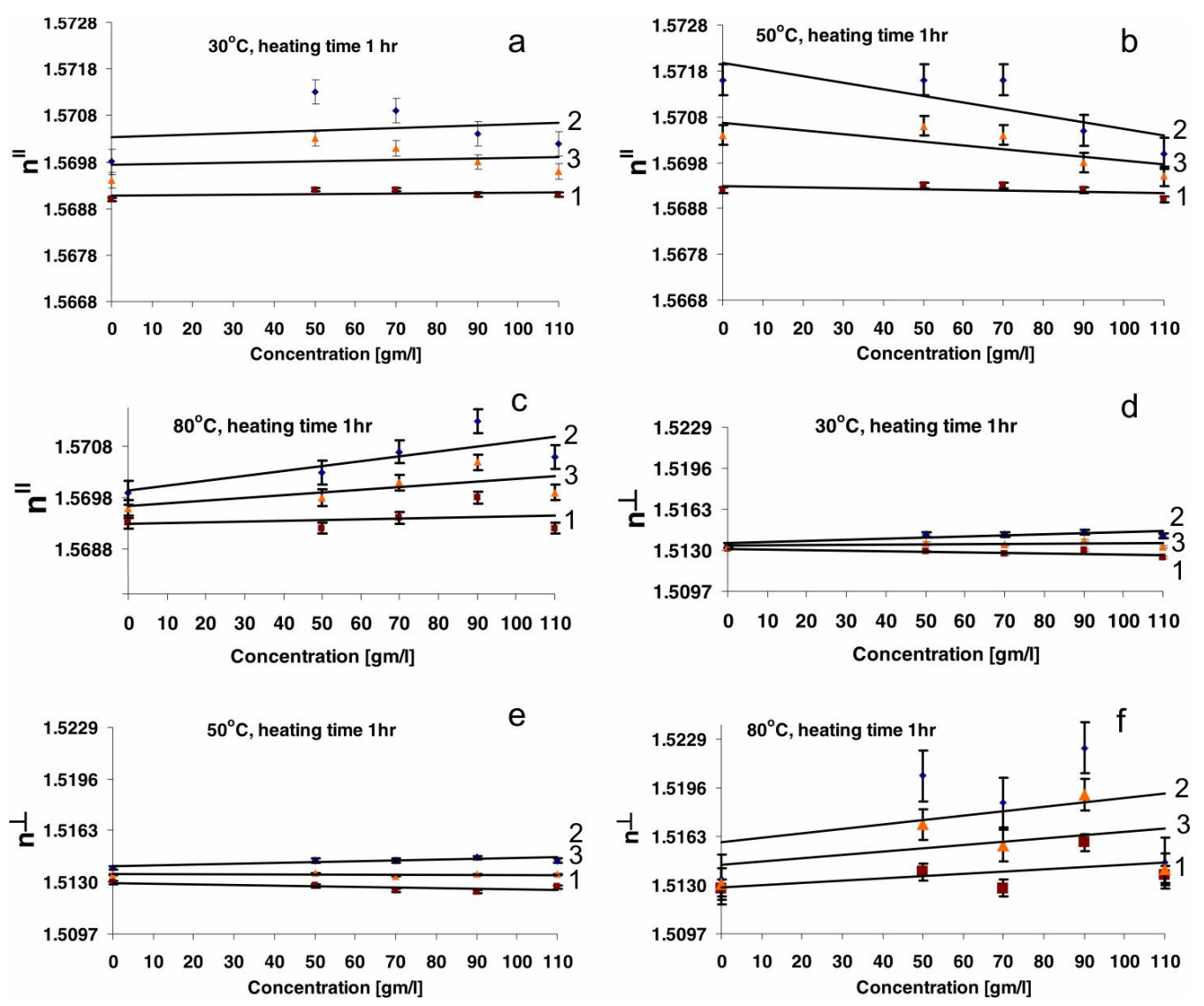

Fig. 4. Refractive indices of the nylon 66 fibres heated in the detergent solution versus solution concentration. The heating times and the temperatures are indicated above the plots. The light polarisation is parallel $(a-c)$ and perpendicular (d-f) to the fibre axis $\left(1-n_{s}^{\|, \perp}, 2-n_{c}^{\|, \perp}\right.$ and $\left.3-n_{a}^{\|, \perp}\right)$. 
Fig. 6 shows the changes occurring in the birefringences $\Delta n_{s, c, a}\left(\Delta n_{s, c, a}=n_{s, c, a}^{\|}-n_{s, c, a}^{\perp}\right)$ due to increasing concentration $(0,50,70,90$ and $100 \mathrm{gm} / 1)$ of the detergent solution. These results have been obtained at different temperatures $\left(30,50\right.$ and $\left.80^{\circ} \mathrm{C}\right)$ and heating times ( $1 \mathrm{~h}$ for the plots $\mathrm{a}-\mathrm{c}$, and $2 \mathrm{~h}$ for the plots $\mathrm{e}-\mathrm{f})$.
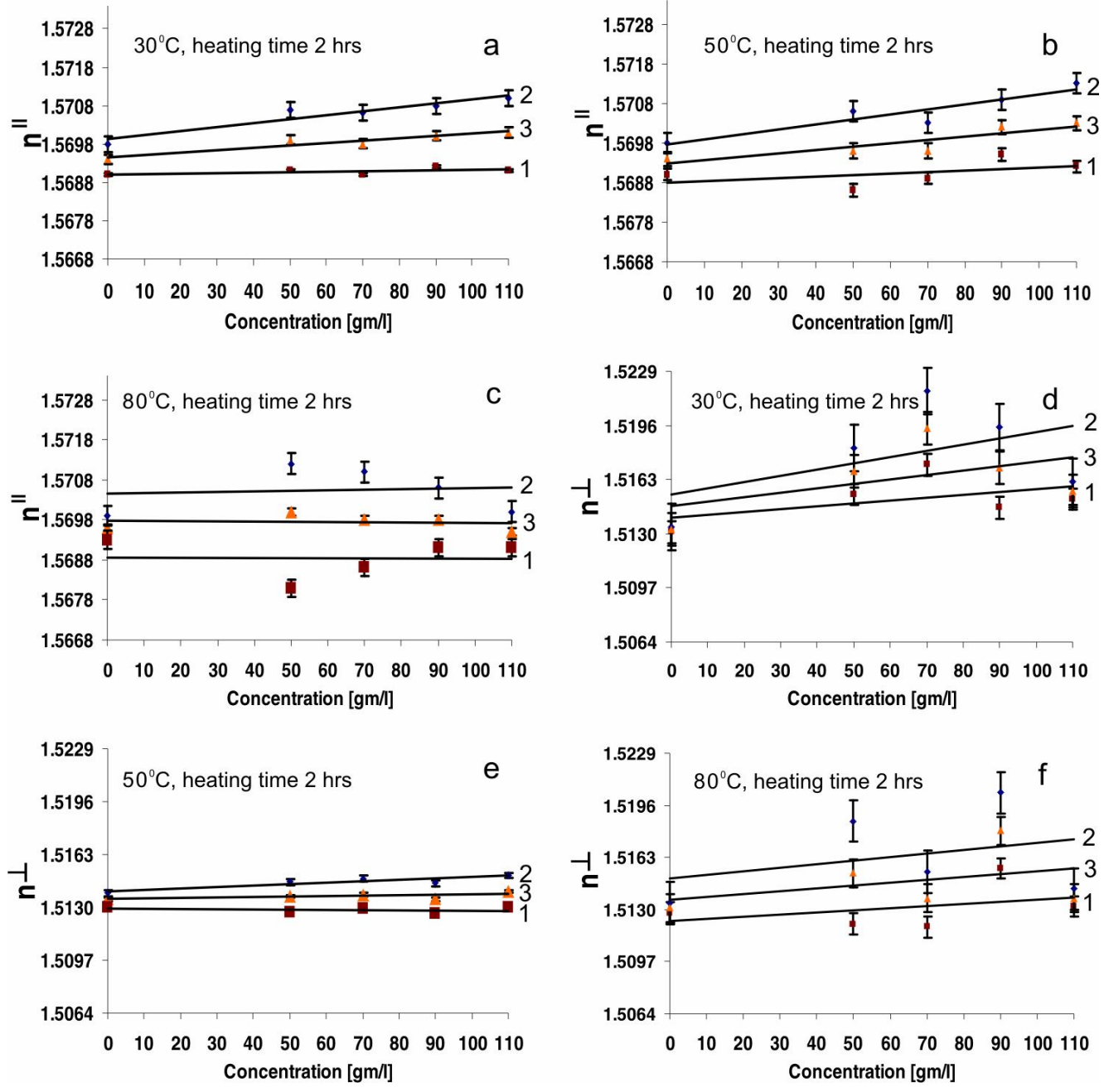

Fig. 5. Refractive indices of the nylon 66 fibres heated in the detergent solution versus solution concentration. The heating times and the temperatures are indicated above the plots. The light polarisation is parallel (a-c) and perpendicular (d-f) to the fibre axis $\left(1-n_{s}^{\|, \perp}, 2-n_{c}^{\|, \perp}\right.$ and $\left.3-n_{a}^{\|, \perp}\right)$ ).

Let us finally touch upon the birefringence, which yields information about the anisotropy and orientation of polymer molecular chains with respect to the fibre axis. Fig. 6 shows the changes occurring in the birefringences $\Delta n_{s, c, a}\left(\Delta n_{s, c, a}=n_{s, c, a}^{\|}-n_{s, c, a}^{\perp}\right)$ due to increasing concentration $(0,50,70,90$ and $100 \mathrm{gm} / \mathrm{l})$ of the detergent solution. These results have been obtained at different temperatures $\left(30,50\right.$ and $\left.80^{\circ} \mathrm{C}\right)$ and heating times ( $1 \mathrm{~h}$ for the plots $\mathrm{a}-\mathrm{c}$, and $2 \mathrm{~h}$ for the plots $\mathrm{e}-\mathrm{f}$ ). 

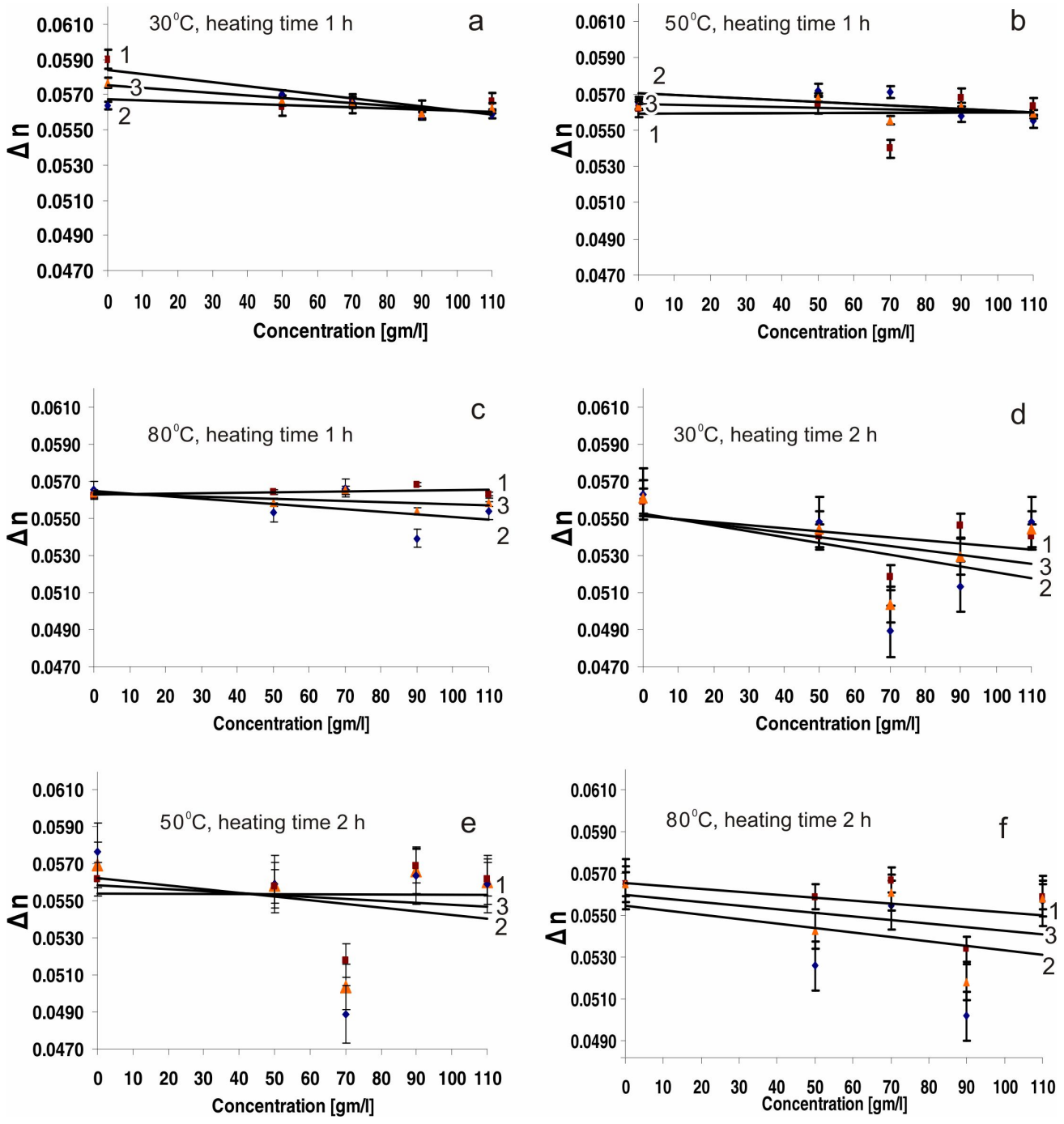

Fig. 6. Birefringences $\Delta n_{s, c, a}$ of the nylon 66 fibres versus concentration of the detergent solution. The heating times and the temperatures are indicated above the plots (1-skin, 2-core, 3-mean).

\section{Conclusions}

Hence, in this work we have studied experimentally the changes in the refractive properties of nylon 66 fibres occurring after their thermal processing under conditions of different temperatures, times and concentrations of the detergent solution.

The following conclusions may be drawn on the basis of our results:

The effect of heating on the nylon 66 fibres is almost independent on both the time and the temperature of heating. The refractive indices obtained for the case of detergent solution are almost independent on the time, the temperature and the solution concentration. The birefringence measured by us does not reveals the effect of the heating temperature, the time and the concentration on the orientation of molecules of nylon 66 fibres. The nylon 66 fibres heated in the water and the detergent solution need further studies in order to elucidate a possible effect of the heating process on the other physical properties. 
Finally, our measurements of such thermo-optic parameters as $n_{a}^{\|, \perp}, n_{s}^{\|, \perp}, n_{c}^{\|, \perp}$ and $\Delta n_{s, c, a}^{\perp}$ have testified that, for the material under test, all of these parameters does not depend upon the temperature conditions.

\section{References}

1. Klein N and Marom G, 1994. Transcrystallinity in nylon 66 composites and its influence on thermal expansively. Composites Polymer. 25: 706-710.

2. Fouda I, 1999. Opto-thermal properties of fibers: 7. Different annealing effects on some optical structural variations of nylon 66 fibers. Polymer Testing. 18: 363-379.

3. Hamza A, Fouda I, Kabeel M and El-Sharkawy M, 1999.Opto-thermal properties of fibres: 5. Structure variations in nylon 66 fibres due to different thermal conditions. Polymer Testing. 18: $155-180$.

4. Kazuya N, Michihiro T and Tisato K, 2002. Aggregation structure and molecular motion of (glass-fiber/matrix nylon 66) interface in short glass-fiber reinforced nylon 66. Composites Polymer. 43: 4055-4062.

5. El-Nicklawy M, Fouda I and Hassan A, 1997. An analysis of Fizeau fringes crossing fibres with different skin-core transverse sections. Polymer Testing. 16: 33-42.

6. Jody $\mathrm{W}$ and Kevin S, 2006. An investigation into the long-term viscoelastic recovery of Nylon 6,6 fibres through accelerated ageing. Mater. Sci. Eng. A. 431: 100-105.

7. Shanfeng W, Gaobin B, Pingping W and Zhewen H, 2000. Viscometric study on the interactions of polymers of the poly(benzazole) family with nylon 66. European Polymer J. 36: 1843-1852.

8. Hamza A, Fouda I, Kabeel M and Shabana M, 1991. Opto-mechanical properties of fibres. 3: Optical properties of Nylon 66 fibres as a function of the draw ratio. Polymer Testing. 10: 305-314.

9. Hamza A, Fouda I, Sokkar T and El-Bakary M, 1996. Opto-thermal properties of fibres: 3-effect of anisotropic optical parameters in polypropylene fibres as a function of annealing process. Polymer Testing. 11: 245-268.

10. Fouda I, El-Nicklawy M, Nasr E and El-Agamy R, 1996. Optothermal properties of fibers. III. Optical anisotropy of nylon 66 fibers as a function of annealing process. J. Appl. Polymer Sci. 60: 1247-1256.

11. Fouda I, El-Nicklawy M, Nasr E and El-Agamy R, 1996. Optothermal properties of fibers. IV. Optical properties of nylon 66 fibers as a function of quenching process. J. Appl. Polymer Sci. 60: 1269-1288.

M.M.El-Nicklawy, R.El-Agmy, A.F. Hassan, Magdy El-Hagary and Amany Adel, 2010. Variations in refractive optical properties of nylon 66 fibres under different thermal conditions. Ukr.J.Phys.Opt. 11: 138-146.

Анотація. У даній роботі методом інтерферометрії досліджені зміни оптичних рефрактивних властивостей волокон - нейлон 66, які виникають при нагріванні води та миючих засобів різної конщентрації. Для визначення показників заломлення сериевини, оболонки, їх середнього значення та двозаломлення використовувався метод багато променевої інтерферометрії Фізо для двох ортогональних поляризаџї світла. 